\section{Pediatric Death from Meningococcal Disease in a Family of Romani Travelers - Sarasota, Florida, 2015}

Eboni Crawford, $\mathrm{MPH}^{1}$; Michael Drennon, $\mathrm{MSPH}^{2}$; Tiffany Winston, $\mathrm{MPH}^{1}$

On January 31, 2015, the Sarasota County Office of the Medical Examiner notified the on-call epidemiologist at the Florida Department of Health, Bureau of Epidemiology of a possible death from meningococcal disease in a male child aged 17 months. The child was part of a large non-English-speaking Romani family (whose members self-identified as Gypsies), who arrived in Florida after traveling in Texas and Europe during the previous 2 months. The child had no history of prior meningococcal immunization. The family reported that the child had been sick for at least 7 days with an ear infection; however, this diagnosis was not confirmed by a physician. Because of increasing fever and onset of vomiting, emergency medical service (EMS) staff members were contacted and the child was transported to a local emergency department on January 29, 2015. Although he was reportedly interactive and alert during registration, he developed a rash while in the emergency department, his condition rapidly deteriorated, and he died within four hours. An autopsy was performed on January 30, and on January 31, the medical examiner reported Gram-negative diplococci in the cerebrospinal fluid (CSF). The on-call epidemiologist notified the Sarasota County epidemiologist to initiate investigation of the case and identify contacts at risk and needing chemoprophylaxis.

In partnership with the Sarasota County Sheriff's Office Romani liaison, who provided translation services, the Florida Department of Health in Sarasota County (DOH-Sarasota) identified 26 family members and other contacts. The hospital-infection-control nurse identified 12 staff members and two EMS transporters whom they believed had significant interaction with the patient. This Romani group indicated that many children and young parents in their community had substantial close contact with the child during his illness. Although a translator was present, communication regarding the meaning of possible exposure was unsatisfactory. Because of the challenges of assessing exposure, the DOH-Sarasota epidemiologist and medical director determined that providing chemoprophylaxis to all identified contacts was necessary.

The DOH-Sarasota epidemiology and clinical staff members opened the agency's health clinic on Saturday, January 31, to provide chemoprophylaxis to the family. Based on published recommendations, persons aged $\geq 12$ years received a single 500-mg oral dose of ciprofloxacin, and persons aged $<12$ years received a single 125 -mg intramuscular injection of ceftriaxone $(1,2)$. Ceftriaxone was chosen because it is administered as a single dose and was easier to administer to children aged $<12$ years than ciprofloxacin.

DOH-Sarasota also provided quadrivalent meningococcal conjugate vaccine to family members to ensure the greatest protection possible. Although immunization of non-adolescents is not routinely recommended, DOH-Sarasota was concerned that the families would leave the area and be lost to follow-up.

In children, signs of bacterial meningitis include inactivity, irritability, vomiting, or poor reflexes in addition to sudden onset of fever, stiff neck, and headache. Because death can occur within hours, prompt medical attention is critical if meningococcal disease is suspected. Actions taken during this investigation highlight the importance of rapid response systems and community partnerships in responding to an event of public health significance. The transient nature of the population, difficulties in communication, and the substantial health risk for meningococcal disease led DOH-Sarasota to elect to provide chemoprophylaxis to all family members who might have had close contact with the infected child. Collaboration with law enforcement facilitated contacting family members and permitted the health department to quickly provide chemoprophylaxis and immunizations to a highly transient, non-English-speaking population. Although these steps went beyond current recommendations, the consensus was that this conservative approach offered the best protection to a hard-toreach population. The Bureau of Public Health Laboratories, Jacksonville, Florida, confirmed Neisseria meningitidis serogroup C cultured from the patient's CSF on February 26. None of the identified social or hospital contacts developed meningococcal disease.

\footnotetext{
${ }^{1}$ Florida Department of Health, Bureau of Epidemiology; ${ }^{2}$ Florida Department of Health, Sarasota County.

Corresponding author: Michael Drennon, Michael.Drennon@flhealth.gov, 941-861-2873.
}

\section{References}

1. American Academy of Pediatrics. Meningococcal infections. In: Pickering LK, Baker CJ, Kimberlin DW, Long SS, eds. Red book: 2012 report of the committee on infectious diseases. Elk Grove Village, IL: American Academy of Pediatrics; 2012.

2. Cohn AC, MacNeil JR, Clark TA, et al. Prevention and control of meningococcal disease: recommendations of the Advisory Committee on Immunization Practices (ACIP). MMWR Recomm Rep 2013;62(No. RR-2). 